\title{
Non-Invasive Imaging for Subclinical Coronary Atherosclerosis in Patients with Peripheral Artery Disease
}

\author{
Rasmus Sejersten Ripa • Andreas Kjaer • Birger Hesse
}

Published online: 2 April 2014

(C) The Author(s) 2014. This article is published with open access at Springerlink.com

\begin{abstract}
Patients with peripheral artery disease are at high risk of coronary artery disease. An increasing number of studies show that a large proportion of patients with peripheral artery disease have significant coronary atherosclerosis, even in the absence of symptoms. Although the reported prevalence of subclinical coronary artery disease varies widely in patients with peripheral artery disease, it could include more than half of patients. No consensus exists to date on either the rationale for screening patients with peripheral artery disease for coronary atherosclerosis or the optimal algorithm and method for screening. An increasing number of imaging modalities are emerging that allow improved in vivo non-invasive characterization of atherosclerotic plaques. These novel imaging methods may lead to early detection of high-risk vulnerable plaques, enabling clinicians to improve risk stratification of patients with peripheral artery disease, and thus paving the way for individualized therapy.
\end{abstract}

Keywords Atherosclerosis · Imaging · Peripheral artery disease

This article is part of the Topical Collection on Cardiovascular Disease and Stroke

R. S. Ripa $\cdot$ A. Kjaer $\cdot$ B. Hesse $(\bowtie)$

Department of Clinical Physiology, Nuclear Medicine and PET,

KF-4012 Rigshospitalet University Hospital, Blegdamsvej 9,

DK-2100 Copenhagen, Denmark

e-mail: birger.hesse@regionh.dk

R. S. Ripa

e-mail: ripa@sund.ku.dk

A. Kjaer

e-mail: akjaer@sund.ku.dk

R. S. Ripa $\cdot$ A. Kjaer $\cdot$ B. Hesse

Cluster for Molecular Imaging, Faculty of Health and Medical

Sciences, University of Copenhagen, Copenhagen, Denmark

\section{Introduction}

Atherosclerosis is a systemic degenerative inflammatory vascular disease and the primary underlying cause of coronary heart disease. Atherosclerosis develops over decades, with a long subclinical period. About half of all patients who die from coronary heart disease have no prior diagnosis or symptoms of cardiac disease [1]. Despite this fact, screening asymptomatic adults for cardiovascular risk by imaging is considered inappropriate in most cases by current guidelines [2].

Clinical risk stratification of asymptomatic patients is typically performed using global risk scores such as the Framingham risk score or HeartScore, rendering a 10-year risk of cardiovascular death on the basis of "classic" cardiovascular risk factors. In addition to the clinical risk scores, a number of medical conditions indicate a cardiovascular risk similar to that of patients with established coronary heart disease [3••, 4]. These coronary heart disease risk equivalents are conditions such as diabetes and peripheral artery diseases (PAD), including lower limb arterial disease, abdominal aortic aneurism, and carotid artery disease. Given the high cardiac mortality and morbidity, early detection and treatment of subclinical coronary heart disease could potentially improve prognosis in patients with PAD.

This article will address the use of imaging methods for identification of subclinical coronary artery disease in patients with known PAD and will discuss the indications for imaging for subclinical coronary artery disease, both with regard to general screening and in the subgroup of patients with PAD who are referred for major surgery.

\section{Prevalence of Subclinical Coronary Artery Disease in Patients with PAD}

More than 30 years ago, Hertzer et al. established that patients undergoing surgical management of PAD had a high 
prevalence of significant coronary artery disease and that a large proportion of the patients were asymptomatic [5]. It is now well documented that patients with atherosclerosis in major peripheral arteries also have a high risk of myocardial infarction [6].

A positive association between carotid and coronary atherosclerosis has been recognized for decades [7]. In the AMISTAD study of 405 patients with acute cerebral infarction [8], 85\% who underwent coronary angiography had no known coronary artery disease. Coronary plaques were found in $62 \%$ and coronary stenoses ( $\geq 50 \%)$ in $26 \%$ of the asymptomatic patients. In addition, the burden of systemic atherosclerosis was determined by ultrasound examination of the carotid arteries, the aorta, and the femoral artery. After adjustment for traditional risk factors, the presence of coronary plaques was significantly associated with the presence of plaques in the carotid and femoral arteries. As was previously suggested by the REACH registry [9], polyvascular disease increased the risk of coronary plaques. In a recent report on clinical followup from the AMISTAD study [10•] both the presence and extent of coronary atherosclerosis were found to predict major vascular events in the 2-year follow-up period.

The prevalence of subclinical coronary artery disease reported in the AMISTAD study is supported by both the PRECORIS study [11] and autopsy studies following fatal stroke [12]. However, a limitation present in both AMISTAD and PRECORIS was the fact that patients were stratified according to known coronary disease (acute coronary syndrome, myocardial infarction, or revascularization), and thus it must be considered that some of these patients could be symptomatic (e.g., having mild angina or angina equivalents) though undiagnosed. If this is the case, one would expect that the prevalence of true subclinical coronary disease is overstated in these trials. Conversely, in a study of 420 patients with significant carotid stenosis, Hofmann et al. [13] found that approximately $60 \%$ of patients without cardiac symptoms had significant coronary stenoses as demonstrated by coronary angiography. It can be speculated that this observed difference in subclinical coronary artery disease is attributable to the differences in the cohorts studied (stroke vs. significant carotid stenosis).

A recent review of the literature including 1,277 patients reported that $50 \%$ of patients with abdominal aortic aneurisms had significant coronary artery disease [14]. This number should be regarded with caution, however, as the studies are heterogeneous with regard to inclusion criteria and methods and span more than four decades. Most of the studies included patients both with and without symptoms of myocardial ischemia. Only two studies specified the prevalence of true subclinical coronary artery disease in patients with abdominal aortic aneurism. Quigley and colleagues reported that $33 \%$ of 102 asymptomatic patients scheduled for surgical repair and screened by myocardial scintigraphy and/or by invasive angiography were found to have significant coronary artery disease [15]. Similarly, Kioka et al. found that $36 \%$ of asymptomatic patients with PAD had significant coronary stenosis $(\geq 75 \%)$ by coronary angiography $[16]$.

Patients with lower limb arterial disease are at increased risk of mortality from cardiovascular and coronary heart disease, even if PAD is asymptomatic [17]. Only a few studies have investigated subclinical coronary disease in patients with lower limb PAD. Her et al. performed coronary angiography prior to peripheral vascular surgery in 82 patients without symptoms of coronary heart disease and found that $70 \%$ had coronary atherosclerosis and $33 \%$ had $\geq 70 \%$ coronary stenosis [18]. In comparison, Hirose et al. performed stress-rest myocardial perfusion imaging in 183 patients with lower limb PAD and found significant presence of ischemia in $55 \%$ of the patients [19]. As some patients were reported to have angina pectoris, a direct comparison of the two studies is difficult. One very recent study included 200 patients with symptomatic lower limb PAD but without angina, dyspnea, or known coronary artery disease $[20 \bullet \cdot]$. Invasive angiography was performed in all patients and showed coronary atherosclerosis in $68 \%$, with significant $(\geq 70 \%)$ coronary stenosis in $55 \%$.

In summary, the reported prevalence of subclinical coronary artery disease in patients with PAD varies widely (Tables 1). This may be attributable, at least in part, to a number of methodological differences. First, the definition of coronary symptoms is variable. For example, should dyspnea, syncope, or an abnormal ECG be designated as coronary symptoms? In addition, lower limb arterial disease may mask coronary ischemia as a result of functional limitations from the PAD. Second, the prevalence seems to vary according to the location of the PAD. Third, the accuracy of the screening method for coronary artery disease will affect the prevalence. Despite differences in reported prevalence, it is clear from all reported series that patients with PAD have a significantly increased prevalence of subclinical coronary artery disease and a high risk of subsequent complications.

\section{Rationale for Screening for Subclinical Coronary Artery Disease in PAD}

Screening for coronary artery disease (CAD) in patients with PAD remains a controversial subject, both in the general PAD population and for selected subgroups, and particularly in PAD patients referred for major surgery.

In patients with PAD who are referred for major surgery, whether for the PAD itself or for other diseases, the risk of postoperative cardiac morbidity and mortality is significantly higher, and preoperative screening for significant CAD is often recommended [21]. However, there is little evidence that supports screening for coronary disease and possible 
Table 1 Prevalence of subclinical coronary artery disease in patients with symptomatic peripheral artery disease

\begin{tabular}{|c|c|c|c|c|c|c|}
\hline Study & Year & Diagnostic modality & $\begin{array}{l}\text { No. of } \\
\text { patients }\end{array}$ & $\begin{array}{l}\text { Kind of } \\
\text { PAD }\end{array}$ & $\begin{array}{l}\text { Prevalence of } \\
\text { coronary stenoses }\end{array}$ & $\begin{array}{l}\text { Symptoms of coronary } \\
\text { artery disease }\end{array}$ \\
\hline Hertzer et al. & 1985 & Coronary angiography & 506 & Carotid & $16 \%$ & No \\
\hline Amarenco et al. & 2011 & Coronary angiography & 405 & Stroke & $26 \%$ & No known CAD \\
\hline Calvet et al. & 2010 & CCTA & 274 & Stroke & $18 \%$ & No known CAD \\
\hline Hofmann et al. & 2005 & Coronary angiography & 420 & Carotid & $60 \%$ & No \\
\hline Hur et al. & $1972-2012$ & Coronary angiography & 1277 & AAA & $50 \%$ & Both symptomatic and asymptomatic \\
\hline Quigley FG et al. & 1999 & Tl-201 SPECT & 102 & AAA & $33 \%$ & No \\
\hline Kioka et al. & 2002 & Coronary angiography & 94 & AAA & $36 \%$ & No \\
\hline Her et al. & 2008 & Coronary angiography & 82 & LEAD & $33 \%$ & No \\
\hline Hirose et al. & 2009 & Tl-201 SPECT & 183 & LEAD & $55 \%$ & Both symptomatic and asymptomatic \\
\hline Marsico et al. & 2013 & Coronary angiography & 200 & LEAD & $55 \%$ & No \\
\hline
\end{tabular}

$\mathrm{AAA}=$ abdominal aortic aneurism, $\mathrm{CCTA}=$ coronary computed tomography angiography, $\mathrm{CAD}=$ coronary artery disease, $\mathrm{LEAD}=$ lower extremity arterial disease, $\mathrm{PAD}=$ peripheral artery disease, $\mathrm{SPECT}=$ single photon emission tomography

interventions as a means of reducing cardiac complications [21].

One recent study included 208 patients with PAD scheduled for major elective vascular surgery with a revised cardiac risk index $\geq 2$ [22]. Patients were randomized to coronary angiography followed by extensive revascularization or to coronary angiography based on the result of ischemia testing (stress-echocardiography or stress-thallium scintigraphy). Revascularization was performed in 61 patients in the first group and 42 in the second group. On follow-up, patients randomized to routine coronary angiography showed better survival and freedom from death/cardiovascular events [22]. Unfortunately, this study did not specify whether any of these patients were without symptoms of myocardial ischemia. Additionally, the study compared two different imaging-derived strategies only. It would have been of interest also to compare to a group treated conservatively with only medication and lifestyle modification but without revascularization.

In the CARP trial, McFalls et al. had determined that revascularization before vascular surgery did not alter longterm outcome when compared to patients randomized to no revascularization [23]. This study included a highly selected cohort of PAD patients with stable cardiac symptoms and coronary angiography showing a significant stenosis. The results supported the contention that many acute cardiovascular events originate from stenoses that are without hemodynamic significance. A new analysis from the CARP trial further demonstrated that only patients with unprotected left main coronary artery disease had a prognostic benefit from preoperative coronary artery revascularization [24].

Patients with stroke are known to have high cardiovascular risk, even with optimal secondary therapy [10•]. One trial investigated the use of systematic preoperative coronary angiography, followed by percutaneous coronary intervention, before carotid endarterectomy in patients without clinical evidence of CAD [25]. All patients $(n=426)$ were without any clinical sign or history of ischemic heart disease. Patients were randomized to 1) angiography and percutaneous coronary intervention if a significant stenosis was detected or 2) no angiography prior to carotid endarterectomy. Systematic angiography was shown to significantly reduce the incidence of postoperative myocardial events. The 30-day survival and stroke rates were equal in the two groups [25]. Limitations of the study included few clinical endpoints and a short follow-up period. In addition, optimal postoperative medical treatment was not part of the study protocol.

If a significant $\mathrm{CAD}$ is demonstrated in the general population of PAD patients without coronary symptoms, should it then lead to medical prophylactic intervention or to coronary revascularization? In fact, very few studies have addressed the prognostic impact of image-guided therapy in this setting. Many will advocate that all patients with severe PAD should already be treated to maximal secondary prevention, and that imaging of the coronary arteries should not alter this treatment, and it is therefore not relevant. Others will advocate that significant coronary artery disease should lead to invasive treatment with percutaneous coronary intervention or bypass surgery in these asymptomatic but high-risk patients. A randomized controlled investigation is sorely needed to address these questions.

In summary, numerous studies have identified severe subclinical CAD in a substantial proportion of patients with PAD, but a beneficial effect of general screening for CAD by either noninvasive or invasive imaging on occurrence of coronary events has yet to be determined. Large prospective randomized trials are needed in order to provide clarity. As a preoperative investigation before intermediate or high-risk cardiac surgery, limited data suggest a beneficial effect of preoperative imaging of the coronary vessels or myocardial perfusion distribution.

From a theoretical risk reduction perspective, a potential benefit in both the general PAD patient population and as a 
preoperative coronary imaging study of subclinical CAD may be the identification of vulnerable plaques that are prone to rupture or to cause thrombus that may subsequently lead to myocardial infarction. Conceptually, this can be accomplished by imaging the plaque, the anatomy of the coronary vessel, or ischemia.

\section{Non-Invasive Imaging of the Coronary Arteries and Coronary Plaques}

In addition to invasive coronary angiography, a considerable number of noninvasive imaging modalities are available that can suggest or demonstrate the presence of coronary artery lesions, either by anatomical or functional or by combined anatomical-functional information showing increased risk of coronary events (Table 2).

\section{Surrogate Measures of Coronary Plaques}

Flow-mediated dilatation is a test to measure endothelial dysfunction and thus a surrogate measure of coronary atherosclerosis. The endothelial dysfunction is measured in the brachial artery using ultrasound. Patients with PAD are known to manifest atherosclerosis, and as endothelial dysfunction is an early hallmark of atherosclerosis, it should be expected that flow-mediated dilation would be attenuated in all patients with PAD. This was demonstrated in a study of 44 patients with
PAD but without symptoms of coronary artery disease [26]. In addition, the authors found that the degree of flow-mediated dilatation could predict the presence of ischemia on myocardial perfusion imaging. Thus far, these intriguing results have not been validated by other studies.

Coronary artery calcium score (CACS) is calculated from a non-contrast $\mathrm{CT}$ of the heart. CACS reflects the total plaque burden and provides incremental prognostic information beyond traditional clinical risk scores (e.g., Framingham and HeartScore) [27]. However, calcification is not a hallmark of vulnerable plaque, and in fact is often seen in stable plaques. CACS, therefore, likely does not image the vulnerable plaque and should be considered a surrogate measure of all plaques, both calcified and non-calcified. Because CACS is a fast, noninvasive, low-cost examination, and subjects the patient to only minimal radiation (typically around $1 \mathrm{mSv}$ ), it may potentially serve as a first-line examination in order to select asymptomatic patients with $\mathrm{PAD}$ who require subsequent coronary examination. A recent report from the prospective GROUND2 study used this approach in a cohort of 111 patents with PAD and no symptoms of cardiovascular disease $[28 \bullet \bullet$. However, only eight of the patients were found to have 0 CACS and no plaques on coronary CT. As such, CACS as a screening method in patients with PAD would likely add very little information, as most patients will have increased score and will require further imaging.

An intriguing perspective of CACS is the fact that it can reclassify risk in subsets of patients. For example, patients

Table 2 Non-invasive imaging modalities for the study of subclinical coronary artery disease in patients with peripheral artery disease

\begin{tabular}{|c|c|c|}
\hline Imaging modality & Advantages & Drawbacks \\
\hline Coronary artery calcium score & $\begin{array}{l}\text { Low price } \\
\text { High availability }\end{array}$ & $\begin{array}{l}\text { Does not visualize non-calcified plaques } \\
\text { Low specificity in patients with PAD }\end{array}$ \\
\hline Coronary angiography by $\mathrm{CT}$ & $\begin{array}{l}\text { High sensitivity for stenotic plaque } \\
\text { Can image plaque morphology } \\
\text { High availability }\end{array}$ & $\begin{array}{l}\text { Ionizing radiation } \\
\text { Plaque imaging technically challenging }\end{array}$ \\
\hline Cardiac magnetic resonance imaging & $\begin{array}{l}\text { Can image plaque morphology } \\
\text { High spatial resolution }\end{array}$ & $\begin{array}{l}\text { Technically very challenging } \\
\text { Limited availability and high cost }\end{array}$ \\
\hline Stress echocardiography & High availability & $\begin{array}{l}\text { Does not visualize plaques } \\
\text { Operator-dependent }\end{array}$ \\
\hline MPI with SPECT & $\begin{array}{l}\text { Prognostic information } \\
\text { Low spatial resolution }\end{array}$ & $\begin{array}{l}\text { Does not image plaque } \\
\text { Ionizing radiation }\end{array}$ \\
\hline MPI with PET & $\begin{array}{l}\text { Image stress induced ischemia } \\
\text { Limited spatial resolution }\end{array}$ & $\begin{array}{l}\text { Does not visualize plaques } \\
\text { High cost and low availability } \\
\text { Ionizing radiation }\end{array}$ \\
\hline FDG-PET/cardiac CT & Combined anatomical and metabolic imaging & $\begin{array}{l}\text { High cost and limited availability } \\
\text { Ionizing radiation }\end{array}$ \\
\hline MPI PET/cardiac CT & Combined anatomical and ischemia imaging & $\begin{array}{l}\text { High cost and low availability } \\
\text { Ionizing radiation }\end{array}$ \\
\hline Specific PET plaque tracer/cardiac CT & Potentially specific identification of vulnerable plaque & $\begin{array}{l}\text { Method still at the experimental level } \\
\text { Ionizing radiation }\end{array}$ \\
\hline
\end{tabular}

$\mathrm{MPI}=$ myocardial perfusion imaging, $\mathrm{PAD}=$ peripheral artery disease, $\mathrm{PET}=$ positron emission tomography, $\mathrm{SPECT}=$ single photon emission computed tomography 
with diabetes and 0 CACS have a cardiovascular event rate similar to patients without diabetes, thereby challenging the notion of diabetes as a coronary heart disease risk equivalent per se [29]. Future studies will need to determine whether this could also apply to patients with PAD.

Another method for imaging calcium is positron emission tomography (PET) using ${ }^{18} \mathrm{~F}$-labeled sodium fluoride (NaF). This tracer is deposited by chemisorptions onto hydroxyapatite and is used in oncology to identify sclerotic bone metastasis. Recent evidence suggests that it is not equivalent to CACS imaging [30] but that it can identify "spotty" calcification in the plaques thought to promote plaque vulnerability. In fact, results from one study indicate that NaF PET can identify culprit and ruptured plaques in patients with recent myocardial infarction [31•].

Compared to both $\mathrm{NaF}$ and particularly CACS, it may be more attractive to image more specific characteristics of the vulnerable plaque.

\section{Anatomical Coronary Plaque Imaging}

Coronary angiography by CT (CCTA) is a non-invasive method using intravenous contrast, typically to assess luminal stenoses. However, it has been shown that CCTA can also provide images of the vessel wall, and thus plaque characteristics, including positive remodeling, densitometry, and calcification [32]. With improved resolution, even small plaques that are not flow-limiting may potentially be assessed for vulnerability characteristics, although the spatial resolution remains a limitation for direct identification of vulnerable plaques [32]. Another challenge for CCTA is the fact that atherosclerosis is a systemic disease typically involving large parts of the coronary arteries. A comprehensive evaluation of coronary plaque morphology by visual evaluation is a cumbersome task. Multisequence magnetic resonance imaging (MRI) is also able to image the coronary artery wall and plaque morphology [33]., This method is even more technically challenging, however, due to cardiac and respiratory motion of the often small tortuous vessels. MRI does appear to be useful for imaging the larger carotid and aortic plaques.

\section{Myocardial Ischemia Imaging}

There are several methods for examining myocardial perfusion, and thus ischemia. Traditionally, this is accomplished by myocardial perfusion single-photon emission tomography (SPECT) using an intravenous injection of ${ }^{99} \mathrm{~m}_{\text {technetium- }}$ labeled tetrofosmin or sestamibi during stress and rest. The use of PET for perfusion imaging is growing and has several advantages compared to SPECT: higher spatial resolution, faster acquisition, fewer motion artifacts, and absolute flow quantification. The perfusion tracers used for PET imaging are ${ }^{82} \mathrm{Rb},{ }^{15} \mathrm{O}$-labeled water, or ${ }^{13} \mathrm{~N}$-labeled ammonia [34]. The primary drawbacks of PET are the limited availability of scanners and perfusion tracers. Both CT and MRI can also image regional myocardial perfusion by dynamic first-pass contrast-enhanced imaging. These methods are less validated in comparison to PET, and particularly SPECT imaging, but the higher resolution is a potential advantage. Dobutamine stress echocardiography combines pharmacological stress with ultrasound imaging to identify left ventricular wall motion abnormalities within the distribution of significant stenotic coronary arteries.

An important advantage of myocardial perfusion imaging is that it is a functional method of imaging perfusion at the myocyte level and thus can determine whether a borderline epicardial stenosis causes a significant change in perfusion. One study $(n=111)$ on the association between PAD and subclinical CAD combined anatomical (CCTA) and ischemia (stress MRI) imaging [28••]. Of 80 patients with plaques on the CCTA (40 with significant and 40 with non-significant stenosis), only 10 were found to have ischemia on subsequent stress MRI.

Perfusion imaging in asymptomatic patients with PAD is useful for identification of areas with silent ischemia, and it is well established that patients without inducible ischemia have very low cardiac event rates (approximately 1\% during the following year [35]). However, patients with established PAD will probably have a higher prevalence of non-stenotic vulnerable plaques that cannot be identified with myocardial perfusion imaging, and the negative predictive value of myocardial perfusion imaging in this patient population will likely be lower, as was previously shown in diabetic patients [36].

\section{Metabolic Imaging of the Vulnerable Plaque}

PET imaging of atherosclerosis has thus far focused primarily on fluorine-18-fluorodeoxyglucose $\left({ }^{18} \mathrm{~F}-\mathrm{FDG}\right)$. The molecule is a glucose analogue that accumulates in metabolically active cells such as macrophages. The first report on ${ }^{18} \mathrm{~F}-\mathrm{FDG}$ accumulation in the large arteries emerged in 2001 [37], and since then, a large body of evidence has materialized linking FDG uptake to the macrophage contents of high-risk plaques [38-40]. This observation is in line with the emerging consensus of atherosclerosis as an inflammatory disease. A major drawback of imaging coronary atherosclerosis with FDGPET, however, is the lack of specificity of the tracer, and another limitation is the high uptake of FDG in the myocardium, which produces a suboptimal signal-to-noise ratio. Consequently, in contrast to FDG imaging of carotid plaques, few studies have utilized FDG-PET to image coronary atherosclerosis $[41 \cdot, 42]$. One recent retrospective study indicated a potential future role of arterial FDG-PET in risk stratification of asymptomatic patients. The authors retrospectively identified 513 FDG-PET examinations and revealed a predictive 
value of arterial FDG uptake for subsequent cardiovascular events in asymptomatic individuals [43].

As an alternative, some researchers have suggested ${ }^{18} \mathrm{~F}$ deoxy- mannose $\left({ }^{18} \mathrm{~F}-\mathrm{FDM}\right)$ as a more specific tracer than ${ }^{18} \mathrm{~F}$ FDG [44], but this needs to be confirmed in clinical trials. To date, no studies have been published on the application of coronary PET imaging in patients with PAD.

\section{Specific PET Tracers for Plaque Imaging}

New and potentially more specific PET tracers for imaging coronary atherosclerosis are emerging [45]. The tracers specifically target the cell-mediated key molecular processes associated with the vulnerable atherosclerotic plaque. The most prominent of these targets include macrophage infiltration, apoptosis, hypoxia, and neoangiogenesis of the intima/ media. As discussed, FDG-PET is capable of imaging macrophage infiltration in the plaques but with low specificity. Another potential target is the somatostatin receptor subtype 2 expressed by macrophages. The somatostatin receptor ligand ${ }^{68} \mathrm{Ga}$-DOTATATE has high affinity for somatostatin receptors, and a few studies have suggested a future role in plaque imaging [46-48]. PET tracers for imaging apoptosis, hypoxia, and neoangiogenesis are available, but their use in coronary artery plaque imaging is extremely limited thus far $[49 \bullet, 50,51]$. A review of new PET and SPECT tracers, as well as tracers used in other modalities, was recently published [52].

\section{Hybrid Imaging}

Hybrid imaging combining anatomical information from a CCTA with metabolic or molecular information from PET imaging may represent a valuable non-invasive modality for the identification of significant microvascular disease and flow-limiting epicardial coronary artery lesions, as well as for demonstration of the characteristics of the vulnerable plaque in selected patients with PAD.

Clinical integrated PET/MRI systems have recently been introduced. MRI can effectively characterize plaque morphology (e.g., hemorrhage and the lipid-rich necrotic core), and the combination with PET-derived molecular imaging holds great potential for in vivo identification of vulnerable plaques. The limited availability of the PET/MRI imaging systems and expensive production of specific PET tracers, however, will likely restrict such a technique to experimental use for some time. Thus far, few reports have been published on hybrid imaging for the study of atherosclerosis [53•], and none have used it for coronary artery imaging. One study combined CACS with CCTA and MRI to identify high-risk PAD patients, but the image selection protocol itself was not validated in the trial $[28 \bullet \bullet]$.

\section{Conclusion}

An already significant and ever-increasing body of evidence indicates a high prevalence of subclinical coronary atherosclerosis in patients with manifest PAD. The value of general screening of coronary arteries with non-invasive imaging in patients with PAD is not documented. Limited data suggest that imaging patients with PAD before major surgery may be valuable. A palette of potentially specific tracers targeted against plaque vulnerability exists via various imaging modalities including PET, CT, MRI, ultrasound, and imaging combinations. Future studies will determine whether identification of patients with PAD at high risk for CAD complications will eventually improve prognosis.

\section{Compliance with Ethics Guidelines}

Conflict of Interest Rasmus Sejersten, Andreas Kjaer, and Birger Hesse declare that they have no conflict of interest.

Human and Animal Rights and Informed Consent This article does not contain any studies with human or animal subjects performed by any of the authors.

Open Access This article is distributed under the terms of the Creative Commons Attribution License which permits any use, distribution, and reproduction in any medium, provided the original author(s) and the source are credited.

\section{References}

Papers of particular interest, published recently, have been highlighted as:

- Of importance

-. Of major importance

1. Ni H, Coady S, Rosamond W, Folsom AR, Chambless L, Russell $\mathrm{SD}$, et al. Trends from 1987 to 2004 in sudden death due to coronary heart disease: the Atherosclerosis Risk in Communities (ARIC) study. Am Heart J. 2009;157:46-52.

2. Greenland P, Alpert JS, Beller GA, Benjamin EJ, Budoff MJ, Fayad ZA, et al. 2010 ACCF/AHA guideline for assessment of cardiovascular risk in asymptomatic adults: a report of the American College of Cardiology Foundation/American Heart Association Task Force on Practice Guidelines. Circulation. 2010;122:e584-636.

3.• Subherwal S, Patel MR, Kober L, Peterson ED, Bhatt DL, Gislason GH, Olsen AM, Jones WS, Torp-Pedersen C, Fosbol EL. Peripheral artery disease is a coronary heart disease risk equivalent among both men and women: results from a nationwide study. Eur J Prev Cardiol. 2014. doi:10.1177/2047487313519344. A nationwide study of more than 100,000 patients identify PAD as a cardiovacular risk factor equivalent to previous myocardial infarction.

4. Perk J, De BG, Gohlke H, Graham I, Reiner Z, Verschuren WM, et al. European Guidelines on cardiovascular disease prevention in clinical practice (version 2012): The Fifth Joint Task Force of the European Society of Cardiology and Other Societies on Cardiovascular Disease Prevention in Clinical Practice (constituted 
by representatives of nine societies and by invited experts). Atherosclerosis. 2012;223:1-68.

5. Hertzer NR, Beven EG, Young JR, O'Hara PJ, Ruschhaupt III WF, Graor RA, et al. Coronary artery disease in peripheral vascular patients. A classification of 1000 coronary angiograms and results of surgical management. Ann Surg. 1984;199:223-33.

6. O'Leary DH, Polak JF, Kronmal RA, Manolio TA, Burke GL, Wolfson Jr SK. Carotid-artery intima and media thickness as a risk factor for myocardial infarction and stroke in older adults. Cardiovascular Health Study Collaborative Research Group. N Engl J Med. 1999;340:14-22.

7. Hertzer NR, Young JR, Beven EG, Graor RA, O'Hara PJ, Ruschhaupt III WF, et al. Coronary angiography in 506 patients with extracranial cerebrovascular disease. Arch Intern Med. 1985;145:849-52.

8. Amarenco P, Lavallee PC, Labreuche J, Ducrocq G, Juliard JM, Feldman L, et al. Prevalence of coronary atherosclerosis in patients with cerebral infarction. Stroke. 2011;42:22-9.

9. Valentijn TM, Stolker RJ. Lessons from the REACH Registry in Europe. Curr Vasc Pharmacol. 2012;10:725-7.

10. Amarenco P, Lavallee PC, Labreuche J, Ducrocq G, Juliard JM, Feldman $\mathrm{L}$, et al. Coronary artery disease and risk of major vascular events after cerebral infarction. Stroke. 2013;44:1505-11. Patient with stroke and subclinical coronary artery stenosis have a high risk of major vascular events within 2 years.

11. Calvet D, Touze E, Varenne O, Sablayrolles JL, Weber S, Mas JL. Prevalence of asymptomatic coronary artery disease in ischemic stroke patients: the PRECORIS study. Circulation. 2010;121: 1623-9.

12. Gongora-Rivera F, Labreuche J, Jaramillo A, Steg PG, Hauw JJ, Amarenco P. Autopsy prevalence of coronary atherosclerosis in patients with fatal stroke. Stroke. 2007;38:1203-10.

13. Hofmann R, Kypta A, Steinwender C, Kerschner K, Grund M, Leisch F. Coronary angiography in patients undergoing carotid artery stenting shows a high incidence of significant coronary artery disease. Heart. 2005;91:1438-41.

14. Hur DJ, Kizilgul M, Aung WW, Roussillon KC, Keeley EC. Frequency of coronary artery disease in patients undergoing peripheral artery disease surgery. Am J Cardiol. 2012;110:736-40.

15. Quigley FG, Clark D, Avramovic J. Cardiac assessment with thallium scanning prior to aortic aneurysm repair. Cardiovasc Surg. 1999;7:640-4.

16. Kioka Y, Tanabe A, Kotani Y, Yamada N, Nakahama M, Ueda T, et al. Review of coronary artery disease in patients with infrarenal abdominal aortic aneurysm. Circ J. 2002;66:1110-2.

17. Criqui MH, Langer RD, Fronek A, Feigelson HS, Klauber MR, McCann TJ, et al. Mortality over a period of 10 years in patients with peripheral arterial disease. N Engl J Med. 1992;326:381-6.

18. Her K, Choi C, Park Y, Shin H, Won Y. Concomitant peripheral artery disease and asymptomatic coronary artery disease: a management strategy. Ann Vasc Surg. 2008;22:649-56.

19. Hirose K, Chikamori T, Hida S, Tanaka H, Igarashi Y, Watanabe Y, et al. Prevalence of coronary heart disease in patients with aortic aneurysm and/or peripheral artery disease. Am J Cardiol. 2009;103: 1215-20.

20.• Marsico F, Ruggiero D, Parente A, Pirozzi E, Musella F, Lo IF, et al. Prevalence and severity of asymptomatic coronary and carotid artery disease in patients with lower limbs arterial disease. Atherosclerosis. 2013;228:386-9. Signficant subclinical coronary disease was observed in 55\% of 200 consecutive patients with lower limb peripheral artery disease.

21. Poldermans D, Bax JJ, Boersma E, De HS, Eeckhout E, Fowkes G, et al. Guidelines for pre-operative cardiac risk assessment and perioperative cardiac management in non-cardiac surgery. Eur Heart J. 2009;30:2769-812.

22. Monaco M, Stassano P, Di TL, Pepino P, Giordano A, Pinna GB, et al. Systematic strategy of prophylactic coronary angiography improves long-term outcome after major vascular surgery in medium- to high-risk patients: a prospective, randomized study. J Am Coll Cardiol. 2009;54:989-96.

23. McFalls EO, Ward HB, Moritz TE, Goldman S, Krupski WC, Littooy $\mathrm{F}$, et al. Coronary-artery revascularization before elective major vascular surgery. N Engl J Med. 2004;351:2795-804.

24. Garcia S, Moritz TE, Ward HB, Pierpont G, Goldman S, Larsen $\mathrm{GC}$, et al. Usefulness of revascularization of patients with multivessel coronary artery disease before elective vascular surgery for abdominal aortic and peripheral occlusive disease. Am J Cardiol. 2008;102:809-13.

25. Illuminati G, Ricco JB, Greco C, Mangieri E, Calio' F, Ceccanei G, et al. Systematic preoperative coronary angiography and stenting improves postoperative results of carotid endarterectomy in patients with asymptomatic coronary artery disease: a randomised controlled trial. Eur J Vasc Endovasc Surg. 2010;39:139-45.

26. Perrone-Filardi P, Cuocolo A, Brevetti G, Silvestro A, Storto G, Dellegrottaglie $\mathrm{S}$, et al. Relation of brachial artery flowmediated vasodilation to significant coronary artery disease in patients with peripheral arterial disease. Am J Cardiol. 2005;96: 1337-41.

27. Detrano R, Guerci AD, Carr JJ, Bild DE, Burke G, Folsom AR, et al. Coronary calcium as a predictor of coronary events in four racial or ethnic groups. N Engl J Med. 2008;358:1336-45.

$28 . \bullet$ den Dekker MA, van den Dungen JJ, Tielliu IF, Tio RA, Jaspers MM, Oudkerk M, et al. Prevalence of severe subclinical coronary artery disease on cardiac CT and MRI in patients with extra-cardiac arterial disease. Eur J Vasc Endovasc Surg. 2013;46:680-9. A novel multimodality non-invasive imaging strategy was employed to identify subclinical coronary artery disease in 111 patents with peripheral artery disease.

29. Raggi P, Shaw LJ, Berman DS, Callister TQ. Prognostic value of coronary artery calcium screening in subjects with and without diabetes. J Am Coll Cardiol. 2004;43:1663-9.

30. Dweck MR, Chow MW, Joshi NV, Williams MC, Jones C, Fletcher $\mathrm{AM}$, et al. Coronary arterial $18 \mathrm{~F}$-sodium fluoride uptake: a novel marker of plaque biology. J Am Coll Cardiol. 2012;59:1539-48.

31. Joshi NV, Vesey AT, Williams MC, Shah AS, Calvert PA, Craighead FH, Yeoh SE, Wallace W, Salter D, Fletcher AM, van Beek EJ, Flapan AD, Uren NG, Behan MW, Cruden NL, Mills NL, Fox KA, Rudd JH, Dweck MR, Newby DE. ${ }^{18}$ F-fluoride positron emission tomography for identification of ruptured and high-risk coronary atherosclerotic plaques: a prospective clinical trial. Lancet. 2014;383(9918):705-13. doi:10.1016/S0140-6736(13) 61754-7. This clinical trial suggests that ${ }^{18} \mathrm{~F}-\mathrm{NaF}$ PET-CT may be able to identify and localize ruptured and high-risk coronary plaque.

32. Obaid DR, Calvert PA, Gopalan D, Parker RA, Hoole SP, West NE, et al. Atherosclerotic plaque composition and classification identified by coronary computed tomography: assessment of computed tomography-generated plaque maps compared with virtual histology intravascular ultrasound and histology. Circ Cardiovasc Imaging. 2013;6:655-64.

33. Karolyi M, Seifarth H, Liew G, Schlett CL, Maurovich-Horvat P, Stolzmann $\mathrm{P}$, et al. Classification of coronary atherosclerotic plaques ex vivo with T1, T2, and ultrashort echo time CMR. JACC Cardiovasc Imaging. 2013;6:466-74.

34. Ghotbi AA, Kjaer A, Hasbak P. Review: comparison of PET rubidium-82 with conventional SPECT myocardial perfusion imaging. Clin Physiol Funct Imaging. 2014. doi:10.1111/cpf.12083.

35. van Werkhoven JM, Schuijf JD, Gaemperli O, Jukema JW, Boersma E, Wijns W, et al. Prognostic value of multislice computed tomography and gated single-photon emission computed tomography in patients with suspected coronary artery disease. J Am Coll Cardiol. 2009;53:623-32.

36. Hachamovitch R, Hayes S, Friedman JD, Cohen I, Shaw LJ, Germano G, et al. Determinants of risk and its temporal variation 
in patients with normal stress myocardial perfusion scans: what is the warranty period of a normal scan? J Am Coll Cardiol. 2003;41: 1329-40.

37. Yun M, Yeh D, Araujo LI, Jang S, Newberg A, Alavi A. F-18 FDG uptake in the large arteries: a new observation. Clin Nucl Med. 2001;26:314-9.

38. Rudd JH, Warburton EA, Fryer TD, Jones HA, Clark JC, Antoun $\mathrm{N}$, et al. Imaging atherosclerotic plaque inflammation with [18F]fluorodeoxyglucose positron emission tomography. Circulation. 2002;105:2708-11.

39. Graebe M, Pedersen SF, Borgwardt L, Hojgaard L, Sillesen H, Kjaer A. Molecular pathology in vulnerable carotid plaques: correlation with [18]-fluorodeoxyglucose positron emission tomography (FDG-PET). Eur J Vasc Endovasc Surg. 2009;37: 714-21.

40. Pedersen SF, Graebe M, Fisker Hag AM, Hojgaard L, Sillesen H, Kjaer A. Gene expression and 18FDG uptake in atherosclerotic carotid plaques. Nucl Med Commun. 2010;31:423-9.

41. Cheng VY, Slomka PJ, Le ML, Tamarappoo BK, Nakazato R, Dey D, et al. Coronary arterial 18 F-FDG uptake by fusion of PET and coronary CT angiography at sites of percutaneous stenting for acute myocardial infarction and stable coronary artery disease. J Nucl Med. 2012;53:575-83. Non-invasive imaging of coronary artery inflammation is feasible by $18 \mathrm{~F}$ FDG PET/CT.

42. Rogers IS, Nasir K, Figueroa AL, Cury RC, Hoffmann U, Vermylen DA, et al. Feasibility of FDG imaging of the coronary arteries: comparison between acute coronary syndrome and stable angina. JACC Cardiovasc Imaging. 2010;3:388-97.

43. Figueroa AL, Abdelbaky A, Truong QA, Corsini E, Macnabb MH, Lavender ZR, et al. Measurement of Arterial Activity on Routine FDG PET/CT Images Improves Prediction of Risk of Future CV Events. JACC Cardiovasc Imaging. 2013;6:1250-9.

44. Tahara N, Mukherjee J, de Haas HJ, Petrov AD, Tawakol A, Haider N, Tahara A, Constantinescu CC, Zhou J, Boersma HH, Imaizumi T, Nakano M, Finn A, Fayad Z, Virmani R, Fuster V, Bosca L, Narula J. 2-deoxy-2-[ $\left[{ }^{18} \mathrm{~F}\right]$ fluoro-d-mannose positron emission tomography imaging in atherosclerosis. Nat Med. 2014. 20(2):215-9. doi:10.1038/nm.3437.
45. Pedersen SF, Hag AM, Klausen TL, Ripa RS, Bodholdt RP, Kjaer A. Positron emission tomography of the vulnerable atherosclerotic plaque in man - a contemporary review. Clin Physiol Funct Imaging. 2014. doi:10.1111/cpf.12105.

46. Li X, Bauer W, Kreissl MC, Weirather J, Bauer E, Israel I, et al. Specific somatostatin receptor II expression in arterial plaque: (68)Ga-DOTATATE autoradiographic, immunohistochemical and flow cytometric studies in apoE-deficient mice. Atherosclerosis. 2013;230:33-9.

47. Rominger A, Saam T, Vogl E, Ubleis C, la Fougere C, Forster S, et al. In vivo imaging of macrophage activity in the coronary arteries using 68Ga-DOTATATE PET/CT: correlation with coronary calcium burden and risk factors. J Nucl Med. 2010;51:193-7.

48. Li X, Samnick S, Lapa C, Israel I, Buck AK, Kreissl MC, et al. 68Ga-DOTATATE PET/CT for the detection of inflammation of large arteries: correlation with18F-FDG, calcium burden and risk factors. EJNMMI Res. 2012;2:52.

49. Beer AJ, Pelisek J, Heider P, Saraste A, Reeps C, Metz S, Seidl S, Kessler H, Wester HJ, Eckstein HH, Schwaiger M. PET/CT Imaging of Integrin avß3 Expression in Human Carotid Atherosclerosis. JACC Cardiovasc Imaging. 2014. 7(2):178-87. doi:10.1016/j.jcmg.2013.12.003. ${ }^{18}$ F-Galacto-RGD PET/CT could be a specific tracer of macrophages and angiogenic endothelial cells in human atherosclerotic lesions.

50. Laufer EM, Winkens HM, Corsten MF, Reutelingsperger CP, Narula J, Hofstra L. PET and SPECT imaging of apoptosis in vulnerable atherosclerotic plaques with radiolabeled Annexin A5. Q J Nucl Med Mol Imaging. 2009;53:26-34.

51. Silvola JM, Saraste A, Forsback S, Laine VJ, Saukko P, Heinonen $\mathrm{SE}$, et al. Detection of hypoxia by [18F]EF5 in atherosclerotic plaques in mice. Arterioscler Thromb Vasc Biol. 2011;31:1011-5.

52. Quillard T, Libby P. Molecular imaging of atherosclerosis for improving diagnostic and therapeutic development. Circ Res. 2012;111:231-44.

53. Ripa RS, Knudsen A, Hag AM, Lebech AM, Loft A, Keller SH, et al. Feasibility of simultaneous PET/MR of the carotid artery: first clinical experience and comparison to PET/CT. Am J Nucl Med Mol Imaging. 2013;3:361-71. Hybrid imaging of carotid arteries using simultaneous PETand MRI is feasible. 